\title{
Clinical Reasoning: Cardioembolic stroke in a 23-year-old man with elbow contracture
}

Bhaskar Roy, MD, MMST, and Elizabeth Raynor, MD

Neurology ${ }^{\circledR}$ 2018;90:e172-176. doi:10.1212/WNL.0000000000004808

\section{Section 1}

A 23-year-old right-handed man with a diagnosis of spinal muscular atrophy (SMA) type 3 presented with right facial droop, hemiparesis, and expressive aphasia. CT angiography revealed a thrombus in the distal left middle cerebral artery. IV tissue plasminogen activator was administered and he recovered without any residual deficit. His cardiac monitoring revealed episodes of atrial fibrillation (figure, C) and episodes of narrow junctional escape rhythm in $20-30$ s. ECG showed normal left ventricular ejection fraction (>55\%). Cardiac MRI showed moderate dilation of right atrium, moderate left atrial elongation, and severely increased left ventricular cavity size with normal systolic function.

Neurologic examination revealed muscle atrophy in a predominantly humeroperoneal distribution. There was mild weakness in deltoid and triceps (4+/5 Medical Research Council [MRC] scale) and moderate weakness in ankle dorsiflexion (3+/5 MRC scale) bilaterally. There were prominent elbow and heel contractures along with exaggerated lumbar lordosis and cervical spine rigidity (figure, A and B). Facial and bulbar muscles were spared. Mild neck flexion weakness was noted. There was no scapular winging. Sensation was intact to all modalities. Reflexes were globally absent. The patient walked on his toes with normal stride.

The patient had an uncomplicated birth history and attained motor milestones appropriately. He was a slow runner and could not keep up with his peers. He was diagnosed with SMA type 3 at age 3 based on EMG and muscle biopsy. Around age 8, he started to develop elbow and ankle contractures. Eventually, he became a toe walker and had frequent falls. He noticed gradual loss of muscle bulk in upper and lower extremities, especially around the shoulder and hip girdle without severe proximal weakness. He had a normal cardiac evaluation with ECG and echocardiogram at age 14 .

\section{Questions for consideration:}

1. Is this phenotype consistent with the diagnosis of SMA type 3 ?

2. What is your differential diagnosis?

\section{Correspondence}

Dr. Raynor

eraynor@bidmc.harvard. edu

From the Department of Neurology, Beth Israel Deaconess Medical Center, Boston, MA.

Go to Neurology.org/N for full disclosures. Funding information and disclosures deemed relevant by the authors, if any, are provided at the end of the article. 
Figure Elbow and heel cord contractures and ECG findings
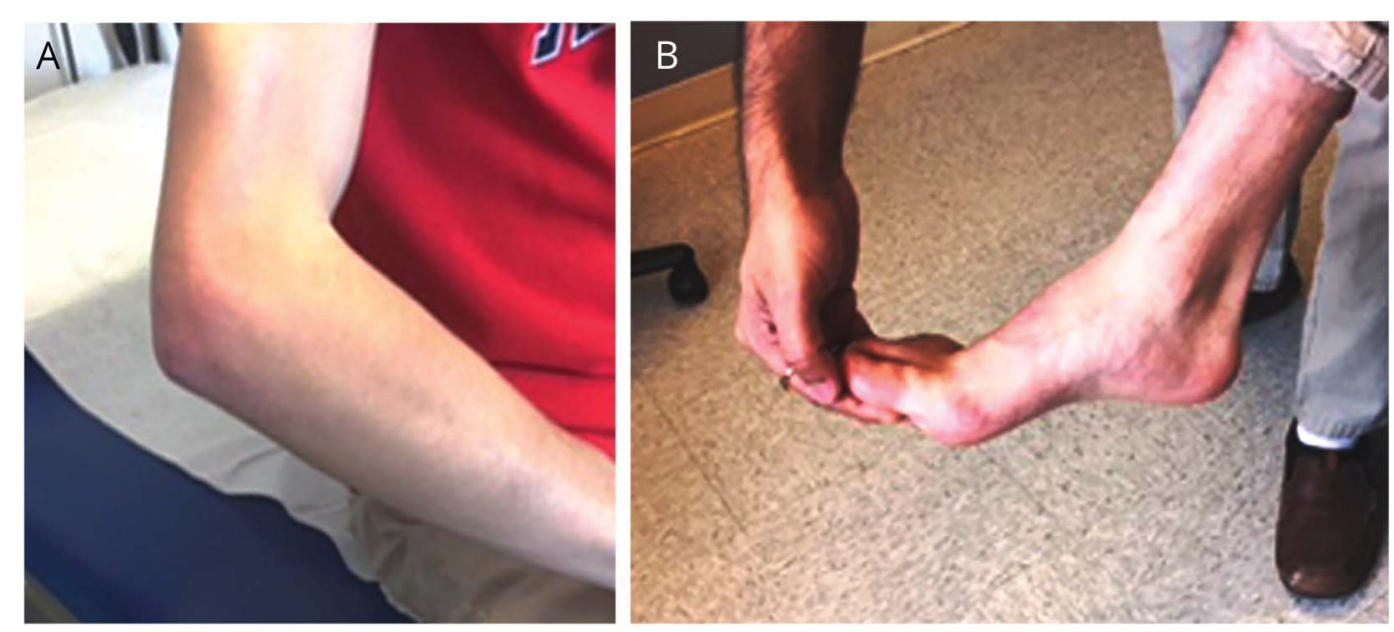

C

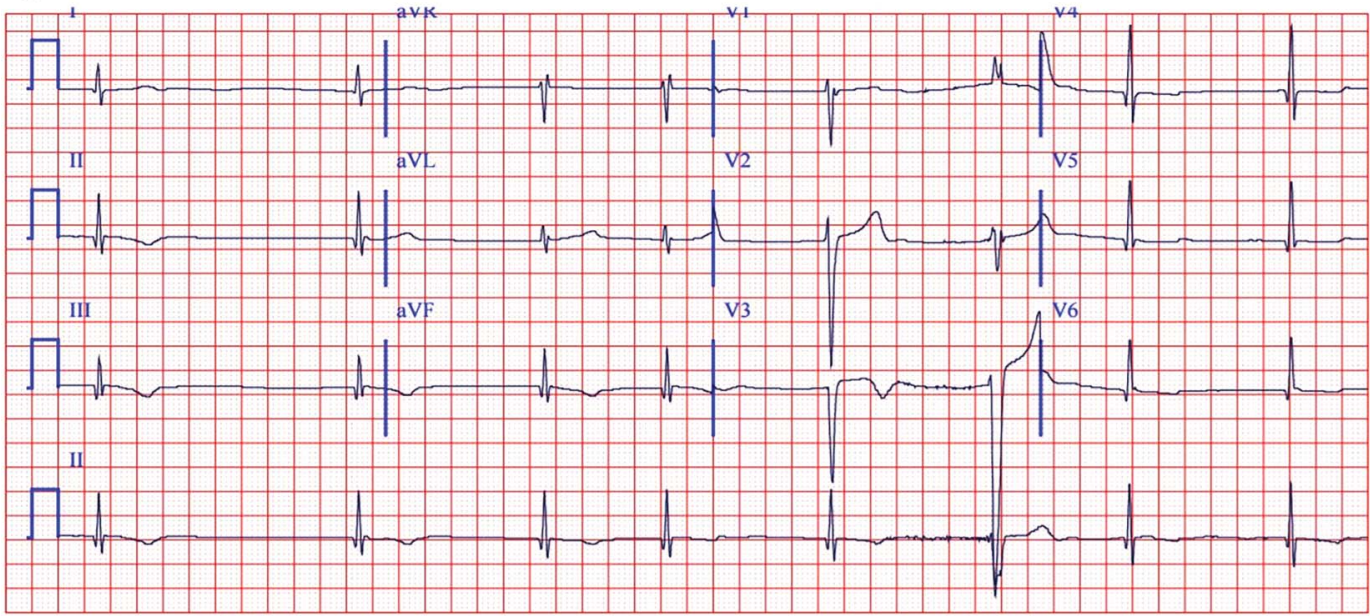

(A) Elbow contracture. (B) Heel cord contracture. (C) ECG shows atrial fibrillation.

GO TO SECTION 2 


\section{Section 2}

Patients with SMA type 3 present with progressive proximal muscle atrophy and weakness, but early development of joint contractures and cardiac involvement is unusual. Joint contractures can be seen in SMA type 1 and type 2 patients only in the setting of severe weakness in nonambulatory patients. Occasionally, early contractures of the heel cord develop in SMA with lower extremity predominance (SMA-LED) from BICD2 mutation or in distal SMAs with TRPV4 mutation. These non-5q SMAs are usually associated with intrauterine involvement or delayed motor milestones, and do not affect the heart. Moreover, elbow contractures would be distinctly unusual in these disorders. ${ }^{1}$ This patient did not have typical phenotype of SMA.

In contrast, early flexion contractures of tendons, especially at the elbow, are a hallmark feature of certain inherited muscular dystrophies, including Emery-Dreifuss muscular dystrophy (EDMD), limb-girdle muscular dystrophy 1B (LGMD 1B), and Bethlem myopathy. ${ }^{2}$

Early-onset elbow, heel, and posterior cervical muscle contractures, humeroperoneal distribution of muscle atrophy and weakness, and cardiac conduction defects are cardinal features of EDMD. EDMD can be X-linked, autosomal dominant $(\mathrm{AD})$, or autosomal recessive (AR). X-linked EDMD (EDMD1) is caused by a mutation in STA located in chromosome xq28 encoding for emerin. Mutations in the FHL1 gene can also present with EDMD phenotype (EDMD6). Mutations in LMNA can lead to both AD (EDMD2) and AR form of EDMD (EDMD3). Rarely, sporadic cases and ADEDMD have been reported in mutations of SYNE1 encoding nesprin-1 (EDMD4), SYNE2 encoding nesprin-2 (EDMD5), and TMEM 43 encoding LUMA (EDMD7). ${ }^{3}$

AD-EDMD and LGMD 1B are overlapping syndromes and allelic disorders caused by mutations in LMNA. However, in $\mathrm{AD}$-EDMD, muscle wasting occurs in a humeroperoneal distribution and in LGMD $1 \mathrm{~B}$ contractures are minimal or absent. ${ }^{4}$ Cardiac involvement in AD-EDMD is ageindependent and can occur in isolation without detectable muscle manifestations. On the other hand, the severity of atrioventricular (AV) conduction disturbances in LGMD 1B is usually age-related and neuromuscular involvement almost always precedes cardiac involvement. Cardioembolic strokes have been reported in both disorders but more frequently in EDMD. $^{5,6}$

Bethlem myopathy is an $\mathrm{AD}$ disorder caused by mutations in COL6A1, COL6A2, and COL6A3. Contractures at the elbow and ankle may be evident, occasionally even before the manifestation of any weakness. However, some patients may have proximal hip and shoulder girdle weakness without contractures. Contractures can be preceded by joint laxity. About $10 \%$ of cases have cardiac involvement including arrhythmia, intraventricular conduction delay, and echocardiogram abnormalities. ${ }^{7}$

Clinically, this patient's phenotype is most consistent with EDMD but a definitive diagnosis cannot be made solely based on clinical features.

\section{Question for consideration:}

1. What is the next best diagnostic test?

GO TO SECTION 3 


\section{Section 3}

Genetic testing would be the next best step. EMG or a muscle biopsy would not discriminate among the disorders under consideration.

Focused genetic testing was performed, which revealed heterozygous mutations in the LMNA gene on c.122G>A (p. Arg41His) and in the TMEM43 gene at c.796C $>\mathrm{T}$ ( $\mathrm{p}$. Arg266Trp). No mutations or exonic deletion/duplications were noted in COL6A1, COL6A2, COL6A3, EMD, FHL1, or SYNE1; thus X-linked EDMD and Bethlem myopathy were ruled out. TMEM43 mutation at c.796CC $>$ T has previously been reported in arrhythmogenic right ventricular cardiomyopathy type $5 .^{3}$

Though previously not reported, the LMNA mutation is most likely pathogenic in this patient. The LMNA gene located in chromosome 1q22 is composed of 12 exons and encodes 4 lamins by alternative splicing. The lamin A and C main isoforms are both nuclear envelope proteins. LMNA can be involved in both EDMD2 and LGMD 1B. They were the first 2 disorders reported to be associated with LMNA mutations. Subsequently, over 400 LMNA mutations have been reported in more than 10 distinct genetic diseases, including dilated cardiomyopathy associated with conduction system disease, congenital muscular dystrophy (L-CMD), AR form of
Charcot-Marie-Tooth type 2B1, Dunnigan type familial partial lipodystrophy, Hutchinson-Gilford progeria syndrome, and mandibuloacral dysplasia. ${ }^{3}$

Different mutations in LMNA can lead to AD-EDMD. Missense mutations are common and $65 \%$ of patients have de novo mutations. Initially, mutations in the rod domain were thought to be solely associated with cardiomyopathy and conduction defects, sparing skeletal muscles; however, various rod domain mutations are now known to cause the full spectrum of EDMD. ${ }^{8,9}$ Usually, patients with missense mutations have early skeletal muscle involvement, whereas frameshift mutations have later onset of muscle symptoms. ${ }^{3,8,9}$

For our patient, this unique mutation in the rod domain was initially considered as a variant of unknown significance. Parental genetic testing did not show the same mutation, confirming the de novo origin and pathogenic nature of the mutation. This exact mutation has not been reported earlier in EDMD; however, another missense mutation (c.122G $>\mathrm{T}$ ) at the same location has been reported in a patient with classic EDMD with atrial standstill. ${ }^{9}$

\section{Questions for consideration:}

1. What is the most serious complication of this disease?

2. How would you manage this patient?

GO TO SECTION 4 


\section{Section 4}

Based on the clinical presentation and genetic testing, our patient has EDMD2. Development of joint contractures can be delayed by a few years in EDMD2 (usually between 3 and 6 years) compared to EDMD1, where the contractures can be the earliest symptom. Weakness in EDMD is generally not profound but cardiac involvement is common and leads to serious complications, including heart failure and sudden cardiac death (SCD). ${ }^{6,8}$

Generally, cardiac manifestations develop with the progression of muscle weakness and after the second decade of life. Cardiac conduction defects are common and range from sinus bradycardia, prolongation of the PR interval, AV conduction block, to complete heart block. Atrial flutter or fibrillation can develop later and may evolve into atrial paralysis. Junctional escape rhythm (40-50 beats/min) without obvious p-waves is the most characteristic ECG finding and atrial paralysis is almost pathognomonic. ${ }^{6,10}$

Frequent cardiac monitoring is essential in EDMD. ECG, Holter monitoring, and 2D echocardiogram every 6-12 months is recommended in asymptomatic patients. National guidelines endorse permanent pacing for patients with EDMD with any degree of AV block, even if asymptomatic, as the progression of $\mathrm{AV}$ conduction disease is unpredictable. SCD can occur even with pacemaker placement. In the absence of guidelines, some authors have suggested prophylactic implantable cardioverter-defibrillator (ICD) placement to prevent possible lethal tachyarrhythmias. ${ }^{6,10}$

Our patient had atrial fibrillation with heart rate in 30 s and attempted DC cardioversion failed. A pacemaker and a single chamber ICD were placed. At the time of his stroke, he was started on anticoagulation. He continues to be asymptomatic in terms of cardiac symptoms although episodes of ventricular tachycardia (with cycle length $>300 \mathrm{~ms}$ ) have been noted on ICD interrogation.

Cardioembolic stroke in a young patient with signs of skeletal muscle involvement should raise the suspicion of an underlying muscular dystrophy. This patient carried a lifelong diagnosis of SMA type 3, although the cardiac conduction abnormalities combined with prominent elbow and heel cord contractures and a humeroperoneal pattern of weakness suggested an alternative diagnosis. Genetic testing confirmed EDMD2 with a novel mutation in LMNA. Early recognition of clinical features and diagnosis of EDMD is critical so that close monitoring and appropriate treatment of cardiac conduction abnormalities may be undertaken to prevent further cardiac complications, including SCD.

\section{Author contributions}

Bhaskar Roy: study concept and design, acquisition of data, analysis and interpretation of data, drafted the manuscript. Elizabeth Raynor: study concept and design, critical revision of manuscript for intellectual content, study supervision.

\section{Acknowledgment}

The authors thank Scott Michalski for helping with details of this patient's genetic testing.

\section{Study funding}

No targeted funding reported.

\section{Disclosure}

The authors report no disclosures relevant to the manuscript. Go to Neurology.org/ $\mathrm{N}$ for full disclosures.

\section{References}

1. Darras BT. Spinal muscular atrophies. Pediatr Clin North Am 2015;62:743-766.

2. Barohn R, Dimachkie M, Jackson C. A pattern recognition approach to patients with a suspected myopathy. Neurol Clin 2014;32:569-593.

3. Amato A, Russell J. Neuromuscular Disorders. 2nd ed. New York: McGraw-Hill Education; 2016:656-718.

4. van der Kooi A, Ledderhof T, DeVoogt W, et al. A newly recognized autosomal dominant limb girdle muscular dystrophy with cardiac involvement. Ann Neurol 1996;39:636-642.

5. Chen C, Tang S, Su Y, Yang C, Jeng J. Cardioembolic stroke related to limb-girdle muscular dystrophy 1B. BMC Res Notes 2013;6:32.

6. Boriani G, Gallina M, Merlini L, et al. Clinical relevance of atrial fibrillation/flutter, stroke, pacemaker implant, and heart failure in Emery-Dreifuss muscular dystrophy: a long-term longitudinal study. Stroke 2003;34:901-908.

7. Pepe G, de Visser M, Bertini E, et al. Bethlem myopathy (BETHLEM) 86th ENMC International Workshop, 10-11 November 2000, Naarden, the Netherlands. Neuromuscul Disord 2002; 12:296-305.

8. Bonne G, Mercuri E, Muchir A, et al. Clinical and molecular genetic spectrum of autosomal dominant Emery-Dreifuss muscular dystrophy due to mutations of the lamin A/C gene. Ann Neurol 2000; 48:170-180.

9. Mardlatillah, Achmad C, Zada A, et al. A novel de novo mutation in lamin A/C gene in Emery Dreifuss muscular dystrophy patient with atrial standstill: a case report. Available at: venicearrhythmias.org/wp-content/uploads/2015/05/M-Affani.pdf. Accessed on September 1, 2017.

10. Meune C, Van Berlo J, Anselme F, Bonne G, Pinto Y, Duboc D. Primary prevention of sudden death in patients with lamin A/C gene mutations. N Engl J Med 2006;354: 209-210. 


\section{Neurology}

\section{Clinical Reasoning: Cardioembolic stroke in a 23-year-old man with elbow contracture Bhaskar Roy and Elizabeth Raynor \\ Neurology 2018;90;e172-e176 \\ DOI 10.1212/WNL.0000000000004808}

\section{This information is current as of January 8, 2018}

\section{Updated Information \& Services}

References

Subspecialty Collections

Permissions \& Licensing

Reprints including high resolution figures, can be found at: http://n.neurology.org/content/90/2/e172.full

This article cites 8 articles, 1 of which you can access for free at: http://n.neurology.org/content/90/2/e172.full\#ref-list-1

This article, along with others on similar topics, appears in the following collection(s):

All Clinical Neurology

http://n.neurology.org/cgi/collection/all_clinical_neurology

All Neuromuscular Disease

http://n.neurology.org/cgi/collection/all_neuromuscular_disease

Muscle disease

http://n.neurology.org/cgi/collection/muscle_disease

Stroke in young adults

http://n.neurology.org/cgi/collection/stroke_in_young_adults

Information about reproducing this article in parts (figures,tables) or in its entirety can be found online at:

http://www.neurology.org/about/about_the_journal\#permissions

Information about ordering reprints can be found online:

http://n.neurology.org/subscribers/advertise

Neurology ${ }^{\circledR}$ is the official journal of the American Academy of Neurology. Published continuously since 1951 , it is now a weekly with 48 issues per year. Copyright Copyright (C) 2018 American Academy of Neurology. All rights reserved. Print ISSN: 0028-3878. Online ISSN: 1526-632X.

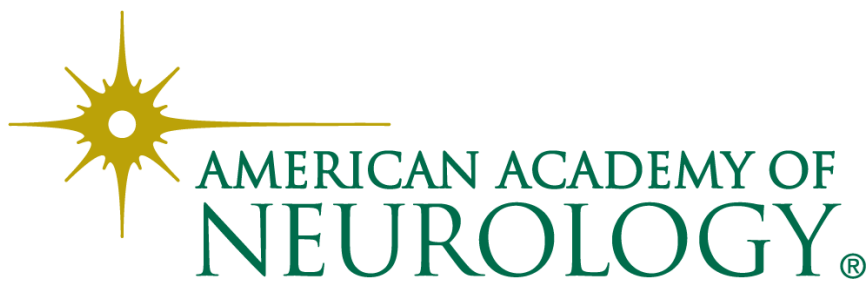

